\title{
A RARE CASE OF PERITONEAL MALIGNANT MESOTHELIOMA OF UNKNOWN ORIGIN PRESENTING WITH ABDOMINAL LUMP
}

Rajiv Hira ${ }^{1}$, V. D. Aironi², Ashutosh Chitnis' ${ }^{3}$, Japnit Singh ${ }^{4}$

\section{HOW TO CITE THIS ARTICLE:}

Rajiv Hira, V. D. Aironi, Ashutosh Chitnis, Japnit Singh. "A Rare Case of Peritoneal Malignant Mesothelioma of Unknown Origin Presenting with Abdominal Lump". Journal of Evolution of Medical and Dental Sciences 2015; Vol. 4, Issue 60, July 27; Page: 10584-10589, DOI: 10.14260/jemds/2015/1528

ABSTRACT: Mesothelioma represents a malignant tumour of the mesotheliomatous cells found in the pleura and peritoneum and is commonly associated with asbestos exposure. ${ }^{1,2}$ Retroperitoneal mesothelioma is quite rare with an incidence of 1-2cases reported per million in the general population each year. ${ }^{3}$ Here, we see a case of a 55 years old right-handed male, farmer by occupation, who presented to MGM Hospital, Navi Mumbai casualty with chief complaints of pain in abdomen and an epigastric abdominal lump since the last 4 months.

\section{CASE REPORT:}

HOPI: A 55 years old right-handed male, farmer by occupation, presented to the MGM Hospital, Navi Mumbai casualty with chief complaints of pain in abdomen and a slowly growing epigastric abdominal lump since the last 4 months. The pain was initially in the epigastric region (more on the left side) and later became diffuse. It gradually increased in intensity over time, it was aggravated on eating and got relieved on applying pressure on the lump. It was non-radiating. There is history of loss of appetite and loss of weight for the last 4 months. The patient has a history of alcohol intake since 10 years. There is no history of asbestos exposure, fever, nausea, vomiting, breathlessness, change of bowel or bladder habits. He declines addiction to tobacco. The patient has no history of diabetes, hypertension, tuberculosis or asthma. He gives no history of any previous abdominal surgery, prior long term medication or any significant family history.

EXAMINATION: On examination, the patient appeared to be of average build and nutrition. No pallor was noted. BP135/85mmHg, Pulse90bpm, RR12/minute. No lymphadenopathy was noted. Cardiovascular, respiratory and CNS examination was normal. On abdominal examination, the abdomen appeared slightly distended with a hard, non-mobile, well-defined rounded swelling/lump felt in the epigastrium with no increase in temperature over the local area. The umbilicus was centrally placed with no scars or sinuses, no dilated veins and there was no visible peristalsis noted. Fluid thrill and shifting dullness were absent.

\section{INVESTIGATIONS:}

Lab:

- Blood Group $\quad$ : B+

- Hemogloblin : $8.7 \mathrm{gm} \%$

- TLC : 8360

- PLATELET COUNT : 1.63

- PCV : 30.90

- $\mathrm{MCV}: 67.20$ 


\section{CASE REPORT}

- $\mathrm{MCHC} \quad: 28.00$

- N57 L 30 M 3 E 10 B 0.

- $\quad$ S.BIL (T) 0.34 (D) 0.07 SGOT 33.3 SGPT 12.3 ALP 5.7 TPR 7.61 ALB 4.06.

- $\quad$ S. CREAT 0.8 UREA 25 URIC ACID 6.4.

- PT/INR 13.9/1.0.

- $\quad$ NA 138 K 4.1 CL 97.

- SERUM AMYLASE 109.

- $\quad$ CA 19-9 1.4.

- HIV/ HBSAG NON REACTIVE.

\section{Radiology:}

1. Chest X-Ray appeared normal.

2. CECT Abdomen was done which shows.

Fig. 1: Non contrast CT scan in sequential sections show large retroperitoneal solid $18 \times 12.5 \mathrm{cms}$ sized iso to hypodense soft tissue mass lesion in the epigastric and left hypochondrium region. The pancreas was not well visualized separately. There is loss of fat plane between spleen and pancreas. Adrenal glands appear normal.

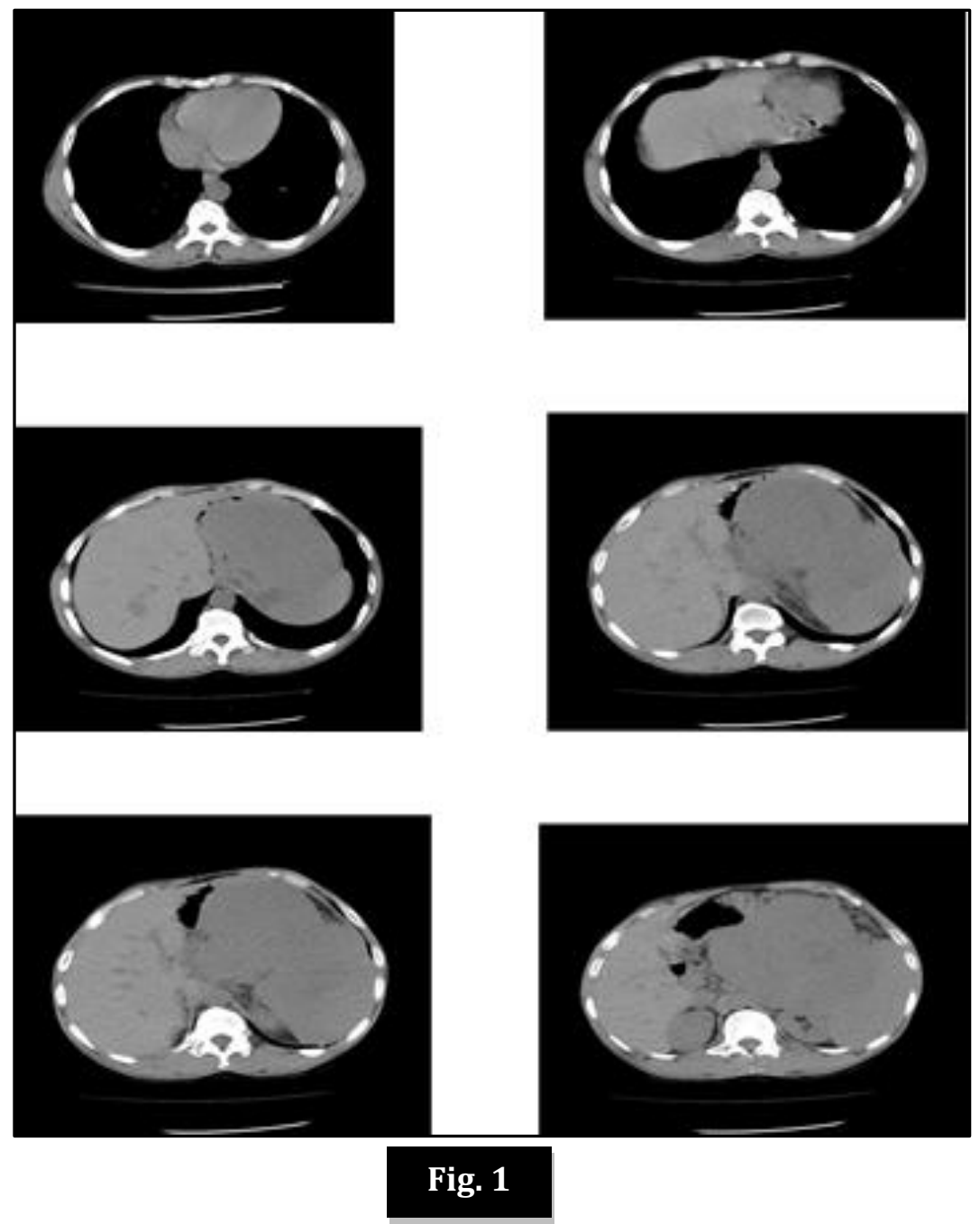




\section{CASE REPORT}

Fig. 2: Contrast Enhanced CT scan shows heterogeneous enhancement of the lesion in arterial phase.
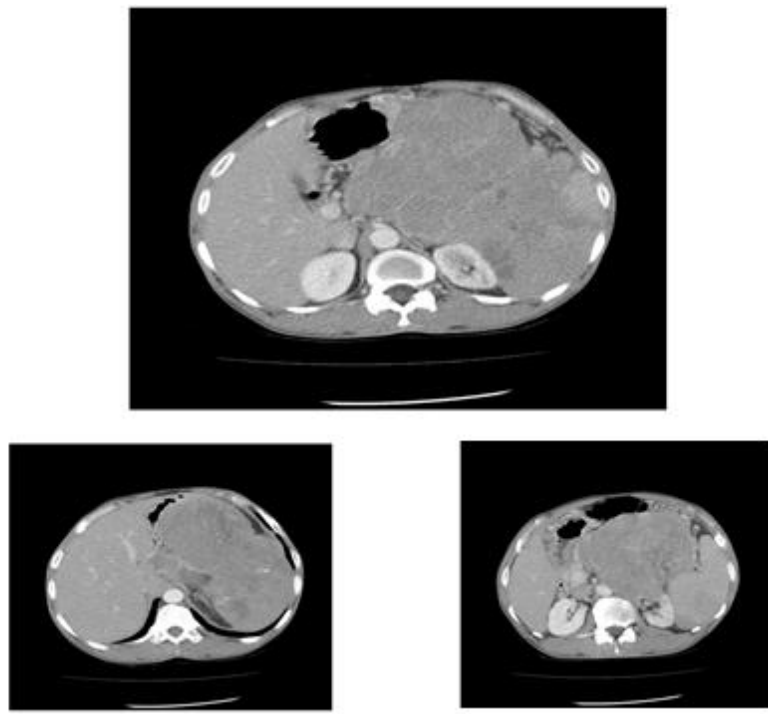

\section{Fig. 2}

Fig. 3: Coronal Sections show displacement of the aorta to right and spleen inferiorly

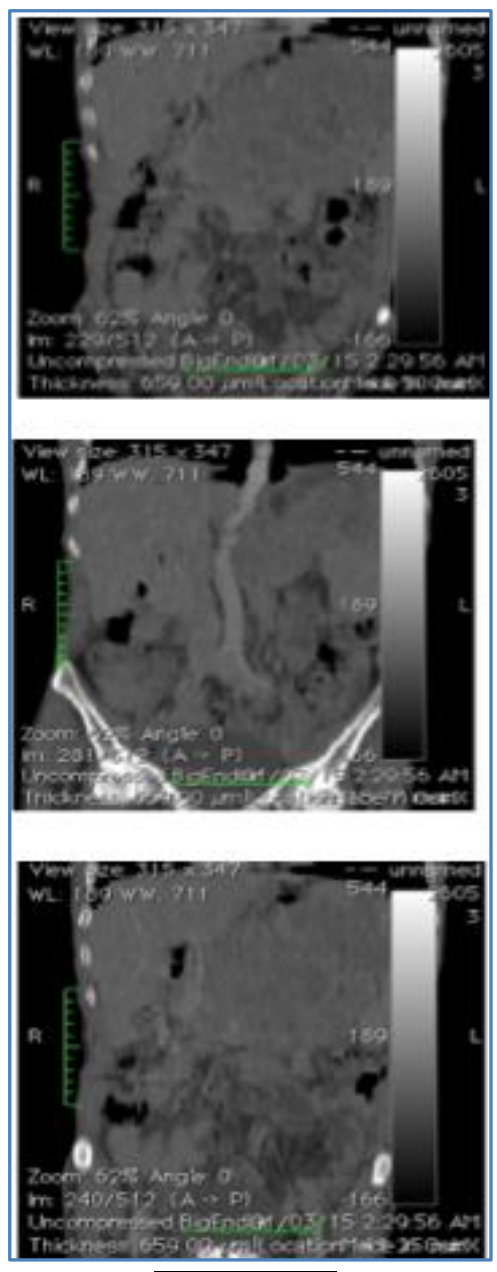

Fig. 3 
3. FNAC revealed Cytomorphological Features Positive for Malignancy

\section{DIFFERENTIAL DIAGNOSIS:}

\section{Based on the CT scan Findings, the Differentials Include:}

I. Pancreatic Adenocarcinoma.

II. Mesothelioma.

III. Gastrointestinal stromal tumour (GIST).

IV. Mesenteric Desmoid Tumor.

\section{Follow-up and Diagnosis:}

- Exploratory laparatomy was done on $12 / 3 / 2015$

- Intra operative findings:

1. Firm, cystic hard mass identified involving superior mesenteric vessels.

2. The mass was apparently coming from below posterior wall of stomach.

3. Omentum adhered to the lump (Omental caking)

- 3 Biopsy samples were taken and sent for histopathology reporting.

- The first 2 sample reports were not conclusive but the 3rd sample report confirmed the diagnosis as mesothelioma!

DISCUSSION: Mesothelioma in general is an aggressive malignant tumour and is strongly associated with asbestos exposure. Majority of these tumors arise from the pleura (Pleural mesothelioma) while other types include peritoneal mesothelioma, pericardial mesothelioma, cystic/multicystic mesothelioma, tunica vaginalis testis mesothelioma. ${ }^{4,5}$

Approximately $15-18 \%$ of all mesotheliomas arise from the peritoneal serosal lining. ${ }^{6}$ About $50 \%$ of cases have no history of exposure to asbestos, although the disease has been seen in patients with prior radiation exposure, exposure to thorium, talc, erionite or mica, as well as in patients affected by familial Mediterranean fever and diffuse lymphocytic lymphoma have also been reported. ${ }^{7}$ The overall incidence is approximately 1-2 cases per million.

Three histologic sub-types exist: epithelial (Most frequent), sarcomatoid and biphasic (Mixed epithelial-sarcomatoid)

The patient typically patients present with weight loss, anorexia, abdominal pain and/or abdominal distension, pyrexia of unknown origin. There can be symptoms associated with hypercoagulability particularly due to paraneoplstic syndrome associated with mesothelioma. ${ }^{8}$

There is a reported correlation between the clinical presentation and CT findings, ${ }^{9}$ with subgrouping into:

- Dry-painful Type: In this type, the patient presents with Abdominal Pain and CT shows features of a peritoneal mass with no (or little) ascites.

- Wet Type: In this type, the patient presents with abdominal distension and CT shows features of widespread nodules (without a mass) along with ascites.

- Mixed Type: In this type, both pain and ascites are present.

\section{To Briefly Discuss the Other Differentials:}

1. Tumours of pancreas are less enhancing than the surrounding pancreatic parenchyma and appear hypodense on CECT in the Arterial phase. In these cases, CT is done majorly to assess 
the relationship with the surrounding vessels specially the Superior Mesenteric Artery and the Iliac plexus. Circumferential involvement indicated unresectability in such cases. ${ }^{10,11}$

2. Gastro-intestinal Stromal Tumor's (GIST) are the most common type of mesenchymal tumours of the gastrointestinal tract. They are most commonly seen in the stomach but may also arise from the small intestine, mesentery, omentum or the retroperitoneum. The best defining feature is its expression of KIT (CD 117) which is a tyrosine kinase factor receptor. ${ }^{12}$ On CT, a GIST appears as a soft tissue density with areas of low density within it because of areas of central necrosis. Also enhancement in these tumours is peripheral due to central necrosis.

3. Mesenteric desmoid tumour is a benign, non-inflammatory fibroblastic tumor with a tendency to local invasion and recurrence but with no metastasis. In the mesentery these might occur sporadically or in association with familial adenomatous polyposis (FAP). CT scan shows a well circumscribed mass which is relatively homogenous/focally hyperattenuating on non-contrast study. On contrast study, most desmoids show enhancement following adminstratuon of contrast. ${ }^{13}$

\section{REFERENCES:}

1. Fontana A, Fuchs P, Otto R. Malignant peritoneal mesothelioma. Schwarz Med Wochenschr. 1976; 106: 555-8.

2. Giles TD, Henderson JC, Dominguez GH. Dominguez GH. Diffuse malignant mesothelioma of the peritoneum. South Med J. 1967; 60: 53-66.

3. Catania V, Bonaccorso R, Fraggetta F, Vecchio S, Grasso F, Cammisuli F, et al. Peritoneal mesothelioma. A case report. Ann Ital Chir. 1996; 67: 697-701.

4. Federle MP, Jeffrey RB, Woodward PJ et-al. Diagnostic Imaging: Abdomen, Published by Amirsys ${ }^{\circledR}$. Lippincott Williams \& Wilkins. (2009) ISBN: 1931884714

5. Dach J, Patel N, Patel S. et-al. Peritoneal mesothelioma: CT, sonography, and gallium-67 scan. AJR Am J Roentgenol. 1980; 135 (3): 614-6

6. Busch JM, Kruskal JB, Wu B et-al. Best cases from the AFIP. Malignant peritoneal mesothelioma. Radiographics. 22 (6): 1511-5.

7. Boffetta P. Epidemiology of peritoneal mesothelioma: a review. Ann. Oncol. 2007; 18 (6): 985 90

8. Whitley NO, Brenner DE, Antman KH et-al. CT of peritoneal mesothelioma: analysis of eight cases. AJR Am J Roentgenol. 1982; 138 (3): 531-5

9. Levy AD, Arnáiz J, Shaw JC et-al. From the archives of the AFIP: primary peritoneal tumors: imaging features with pathologic correlation. Radiographics. 28 (2): 583-607

10. Kawamoto S, Horton KM, Lawler LP et-al. Intraductal papillary mucinous neoplasm of the pancreas: can benign lesions be differentiated from malignant lesions with multidetector CT? Radiographics. 25 (6): 1451-68.

11. Ferrozzi F, Zuccoli G, Bova D et-al. Mesenchymal tumors of the pancreas: CT findings. J Comput Assist Tomogr. 24 (4): 622-7

12. Levy AD, Remotti HE, Thompson WM et-al. Gastro intestinal stromal tumors: radiologic features with pathologic correlation. Radiographics. 23 (2): 283-304, 456

13. Einstein DM, Tagliabue JR, Desai RK. Abdominal desmoids: CT findings in 25 patients. AJR Am J Roentgenol. 1991; 157 (2): 275-9. 


\section{CASE REPORT}

\section{AUTHORS:}

1. Rajiv Hira

2. V. D. Aironi

3. Ashutosh Chitnis

4. Japnit Singh

\section{PARTICULARS OF CONTRIBUTORS:}

1. Resident, Department of Radiology, MGM Hospital, Kamothe, Navi Mumbai.

2. Associate Professor Department of Radiology, MGM Hospital, Kamothe, Navi Mumbai.

FINANCIAL OR OTHER

COMPETING INTERESTS: None
3. Associate Professor, Department of Radiology, MGM Hospital, Kamothe, Navi Mumbai

4. Resident, Department of Radiology, MGM Hospital, Kamothe, Navi Mumbai.

\section{NAME ADDRESS EMAIL ID OF THE}

\section{CORRESPONDING AUTHOR:}

Rajiv Hira,

502, Debonair Apartments,

Cadell Road, Mahim (W),

Mumbai-400016, India.

E-mail: rajivhira@gmail.com

Date of Submission: 06/06/2015.

Date of Peer Review: 07/06/2015.

Date of Acceptance: 21/07/2015.

Date of Publishing: 27/07/2015. 